https://www.amerabra.org; https://fspu.uitm.edu.my/cebs; https://www.emasemasresources.com 9th Asia Pacific International Conference on Environment-Behaviour Studies, Faculty of Architecture, Ulisboa, Lisbon, Portugal, 03-04 Jul 2019

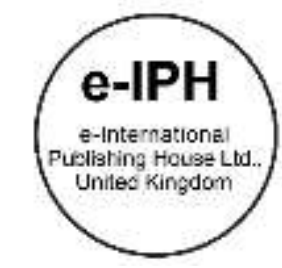

\title{
Perception of Local Identity to Roi-et Provincial Hall
}

\author{
Phatlalitsorn Kaewpeela ${ }^{1}$, Karuna Raksawin ${ }^{2}$, Supagtra Suthasupa ${ }^{3}$
}

\author{
1 Graduate Student, ${ }^{2}$ Associate Professor Dr., Faculty of Architecture, \\ Chiang Mai University, Chiang Mai 50200, Thailand. \\ ${ }^{3}$ Assistant Professor Dr., Faculty of Architecture, Silpakorn University, Bangkok 10200, Thailand.
}

phatlalitsorn.k@gmail.com, karuna.r@cmu.ac.th, supakoy@gmail.com

Tel +66 53942806

\begin{abstract}
For more than 80 years, Roi Et established a city hall followed to the legislative requirement. Last year in 2018, Roi Et provincial office planned to remodel the city hall building to replace the former buildings which were dilapidated. So, this research aims to evaluate the local perception of Roi Et city hall. The methodologies to test the architectural perception of the Roi Et city hall is the sketch presenting to the pictures of the redesigned Roi Et city hall displayed with the questionnaire. The results reveal that people have the perception of the local architectural style.
\end{abstract}

Keywords: local identity; visual perception; Roi Et; city hall

eISSN: 2398-4287 @ 2019. The Authors. Published for AMER ABRA cE-Bs by e-International Publishing House, Ltd., UK. This is an open access article under the CC BYNC-ND license (http://creativecommons.org/licenses/by-nc-nd/4.0). Peer-review under responsibility of AMER (Association of Malaysian Environment-Behaviour Researchers), ABRA (Association of Behavioural Researchers on Asians) and cE-Bs (Centre for Environment-Behaviour Studies), Faculty of Architecture, Planning \& Surveying, Universiti Teknologi MARA, Malaysia.

DOI: https://doi.org/10.21834/e-bpj.v4i11.1715

\subsection{Introduction}

The city hall is one of the most critical factors of the city because it is the place where the provincial administration located. The city hall represents the administration center in every province in Thailand. Together with architectural recognition, the city halls in every region have the same pattern to acknowledge equality (Churstarponsiri, 2001). The changes happened when the government center management committee said that the government building has to represent the local identity (The Secretariat of the Cabinet, 2010), which does not go along with the previous idea. By regionalism, which mentions about the relationship between architecture and its settlement, displayed different of the international standards from the Modernism and Post Modernism architecture (Lorchai, Panin, \& Kerdsiri, 2015). This idea is the reason to support the relationship between the city hall and local identity.

The present city hall affected by design during 1932 - 1979. And later in 1980, in the term of General Prem Tinsulanonda as Prime Minister, at that time, the direction of national administration aimed to distribute income and economic development (National Economic and Social Development Plan no.4 between 1977-1981). The number of government officials had increased. To keep the same direction of national identity on government office, the setting up committee to consider the government office in Bangkok and other major cities was established. In 1996, the Prime Minister Office had announced the administration of the Government Center and set up the two sub-committees to supervise the government centers in every province. The Government Center will be not only for governors so that the government center management must concern many dimensions. In that period, there was a different context from the present, which leads to the question of this study.

Since the past, the style of the town hall has changed according to the era and government policy. From the beginning, it was practically the governor's office was a wooden building based on local architectural styles. The characteristics depended on the local builder and the richness of the ruler and was built with the personal statements of the governor. The change was taken Western architectural styles from foreigners and Thai people who returned from the overseas. Later, the standard model was used to design throughout the country in the form of Thai architecture. After having the idea of the establishment of a government center, the design of

eISSN: 2398-4287 ( ) 2019. The Authors. Published for AMER ABRA cE-Bs by e-International Publishing House, Ltd., UK. This is an open access article under the CC BYNC-ND license (http://creativecommons.org/licenses/by-nc-nd/4.0/). Peer-review under responsibility of AMER (Association of Malaysian Environment-Behaviour Researchers), ABRA (Association of Behavioural Researchers on Asians) and cE-Bs (Centre for Environment-Behaviour Studies), Faculty of Architecture, Planning \& Surveying, Universiti Teknologi MARA, Malaysia.

DOI: https://doi.org/10.21834/e-bpj.v4i11.1715 
the town hall is a combination of Western architecture, applied Thai architecture and vernacular architecture but still using the standard model by the Department of Town Planning.

At present, the new town hall building is being constructed and replaced the old building which is small size in many provinces of Thailand. Although there was a resolution from the cabinet, considered the design and layout of the buildings within the government center to be consistent with local architectural styles for the uniqueness of each government center and facilitated the service to the people. But when looking at the city hall in many places, it was impossible to determine where the town hall is in which region of Thailand. And with cultural, tradition and architectural style differences, the city hall has a similar look, not different.

The study of the city hall design that shows local identity so that the population in the area is accepted is very important. To be a guideline for the design of the city hall or other government buildings to be accepted in the public, creating a relationships between the government and the public, bring the confidence and partnerships, as well as supporting the policy of promoting identity Local according to the resolution from the cabinet. This study aims to test the local identity perception of Roi Et city hall. The local identity perception is directly related to the local style. With their experiences, the information of the local identity has recognized day by day via the visual responses. The perception can interpret the image and match the cognition. When the photos represent the identity of local and affect the local recognition, the architectural style may be called the local form.

\subsection{Theory, Literature, and Related Research}

\subsection{Background of Roi Et and its Location}

Roi Et province is in the northeastern region in Korat civilization and Chi-Mun River, which is called the South Isan group. Their culture from the Khmer art began to appear the stone castles of Khmer culture (Wongthes, 2012). During the seventeenth century of Buddhism, there was an expansion of the Khmer Kingdom throughout the Isan region from the lower northeast area to the central Northeast and more Northeast Roi Et. This period was one of the central cities in the sub-region level (Sutthitham, 2001). There were Khmer stone castles scattered throughout the area. After that, during the twentieth century (Buddhism era), the trade routes, religious and political had changed. There was a relocation which mainly caused by Lao people. The Khmer art such as stone castles was a reconstruction to Lao style (Wongthes, 2012, p.64-68). There are two ethnic groups: The Northside contain Phra That Phanom, Lan Chang Art is the sacred center; The Southside has Wat Phu Champasak Temple, Khmer Art is a holy center (Wongthes, 2012). It influenced Roi Et has a mixture of Lan Chang art and Khmer art, but the intensity of Khmer culture is more intense. The features of the stone castle in Khmer culture due to its form is clearly understood and suitable for redesign the Roi Et city hall.
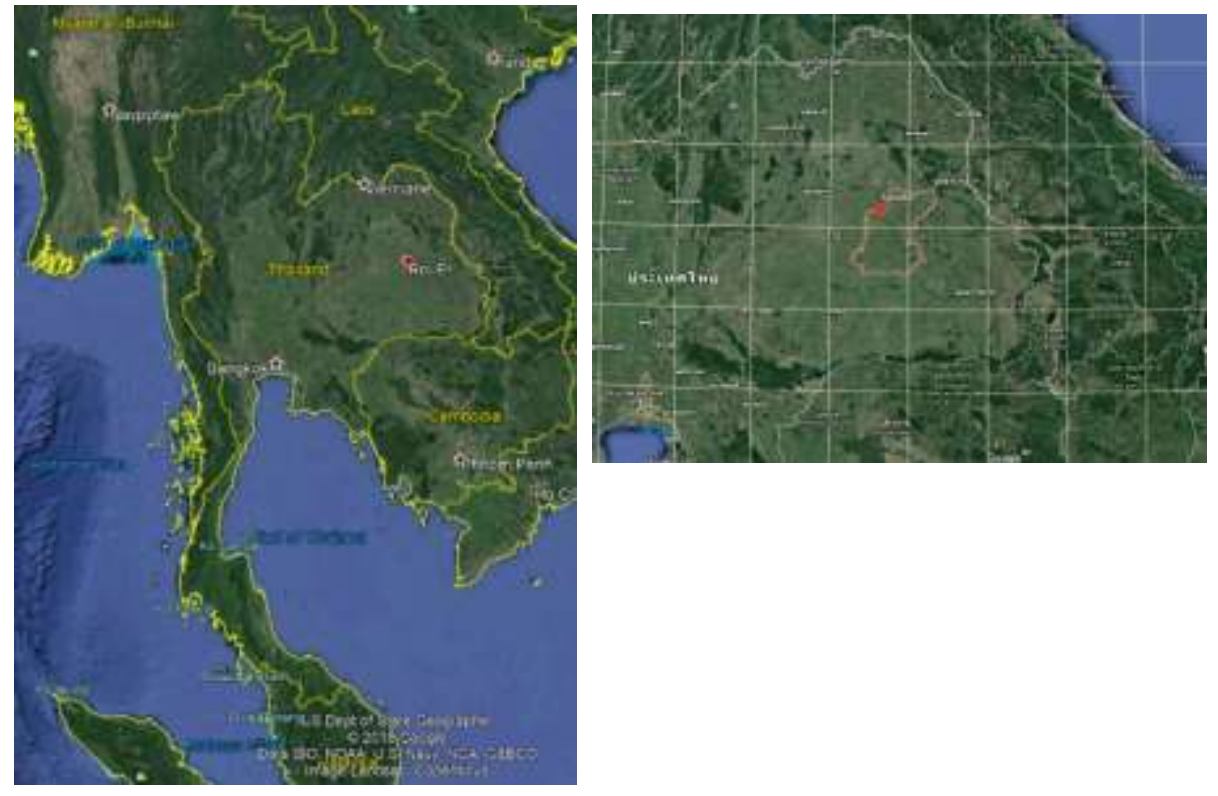

Fig. 1: Roi Et Location

\subsection{Local Identity and Roi Et city hall}

According to the Royal Thai Academy, the word "identity" means a unique property. In the architectural context, it usually refers to the language that represents context, location, or culture, which used to describe the culture (Suwatcharapinan et al., 2012). This kind of style is more complicated than the original language because there are two levels of communication. At the first level, the architecture must link to the culture inspired. And the second level, architecture is needed to communicate to the building users inevitably. This means studying local identities in the design as a result of studying the cultural content of that locality and using one of the methods to communicate meaning from cultural content to architecture, including communication to the building user. If looking at the location of Roi Et province, is in the northeastern (Isan) region of the Korat civilization, which is called the Chi-Mun River basin, has the same 
cultural consistency as the provinces in the South Isan group which continues the culture from Khmer art. In the 15th century, Khmer culture came to Roi Et. It began to appear that there were stone castles in Khmer culture in the area. And during the 17th-18th century, there was an expansion of the Khmer Kingdom throughout the northeastern region from the lower northeast to the central northeast and the upper northeastern part, resulted the influence of art from Khmer and worshiping the gods in the Brahmin religion of the upper class. There were stone castles scattered throughout the area, which was different from the first era that was a ghost-respecting society. After that, during the 20th century, there were changes in the trade routes, religious and political changes of the state, relocations to other places, causing the Caesar and Lao to relocate instead of the original, resulted in Khmer art such as various stone castles rebuilt to be Lao style, making Roi Et influenced by cultural changes according to the occupation of the area. Although Roi Et has the form of a mixture of Lan Chang art and Khmer art, but the concentration of architectural styles in Khmer culture remains clear. The language that is chosen for the design to be conspicuous to Roi Et is therefore chosen to use the characteristic of the culture that is the evident in the South Isan area. Which is in the civilization basin of Korat as well as Roi Et. It is a clearly understood form that is suitable for use as a precursor in the study of communication to the area of the South Isan.

The standard style of Thai city hall had a registered design for almost forty years. The conceptual idea from the central administration pushed the city hall standard style via the control of the government center committee. The critical tool is set with the budget supporting. If the city hall planned to construct this year, the process to fiscal plan should be submitted three years formerly. The three years duration is the process of negotiation and calibration. The standpoint of financial consideration is the most valuable the first. So, the city hall with a standard style has more expensive than the tailored made. This functionalism has willing to promote for three decades. In recent years, the idea of local identity is talking a lot in many dimensions. For example, the drama of heritage city, the promotion of local identity faced the alternative procedures, one way to conservation, the other to contemporary. Either way can be solved the local identity expression.

The architecture style after the political reformation during 1932 - 1979, divided into eight factors (Tiptus,1996; Sukkata, 2001; Horayangkura et al., 1993; Argsakorn, 1985; Ratkasikorn, 1997 as cited in Churstarponsiri, 2001, p.155-157) as the followings,

1. There was a strong standardization of the system involved, such as creating a standard design of the centralized government and assigned the Department of Public Works to build throughout the Kingdom.

2. These standards divided in rank base on the province's priority.

3. There was a law to set the town hall in the local administrative area in the form of a municipality, determined to call the district of the province to be in an area surrounded by offices of other government offices.

4. Two essential elements must be included in the layout, a city hall, and the plaza for state ceremonies and public meetings.

5. There was the plan based on the Western architectural style together with the Modern concept, which was the principle of architecture throughout the world in that era. The layout of the plan had axial clamping, and the balance of the shape had been forced a rectangular room.

6. The reinforced concrete was the primary material for construction. Small roofing cement tiles with a slight curvature of the roof according to the characteristics of the Thai roof complied with the method of the western idea.

7. The main idea was the national identity. Therefore, maintaining the form of temples and palaces, which was an ancient Thai architecture and Thai tradition had further developed by reducing the conversion and adding to the original Thai. The highlight was the borrowing of the gable roof with the concrete stucco.

8. There was a characteristic of using the building porch, to create a gable roof that was decorated or affixed the government symbols.

\subsection{Human perception in architecture (City Hall)}

The process of knowledge begins with the stimulus of the five senses, such as visual stimuli through the eyes. The brain will remember and record as an experience from the stimuli. Then, it will interpret the meaning of what has been reached and processed with the later memories and make a learning process and lead to decisions making (Waranusantikul, 2004, as cited in Saiseng, 2017). The recognition process consists of sensation, perception, and cognition, where all operations are consistent and cannot be separated (Phetsuriya, 2013).

The connection between recognition and architecture are involved, inevitable, or perceived through the visual senses. At the same time, the emergence of architecture must take into the image of the architecture because it has the human relationships and awareness which lead to the design of shape, proportion, area, as well as the building system.

The image of the city hall is a representative centralized power (Churstarponsiri, 2001). The critical issue is the recognition in the image of the city hall. The question arises that the building in this standard is enough to recognize the local identity, or not. Sanboon (2014) had written an article about Khmer style in contemporary Isan technicians that reflected their own culture.

\subsection{Study Method}

The study of local identity in Roi Et city hall had planned to evaluate the local identity perception on Roi Et city hall reconstructing project. The renovation of this building put a characteristic of local identity in parallel with the design. The most apparent method of considering visual perception through photos was decided. Then, an online questionnaire was a process of testing.

\subsection{Model selection in identity recognition}

Tok, Kaplan, and Taneli (2010) use photo as a tool to study architecture and evaluate the social perspective of the environment. They 
said that photo as a tool is a popular method in Anthropology and Psychology study. The interpretation process by image is to unfold the meaning of different levels of the evaluators' perspective, whether it is about materials, society, behavior, or culture. (Elkins, 2003 as cited in Tok, Kaplan, \& Taneli, 2010)

The study of identity recognition in South Isan (Northeastern region of Thailand) uses the perception test. The photo samples show the city hall design, which is like the Kopura or the arch of the stone castle, which is one of the stable architectural features in the South Isan area.

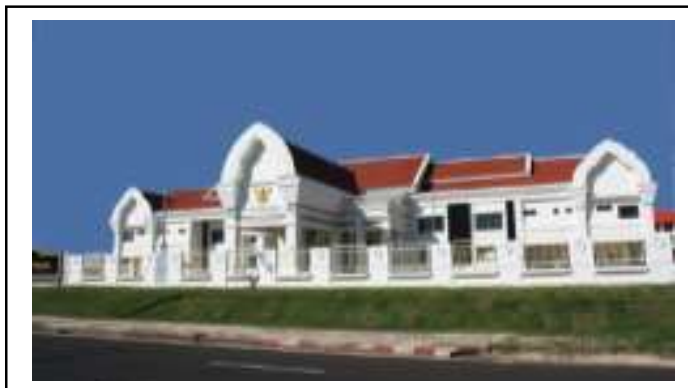

(a)

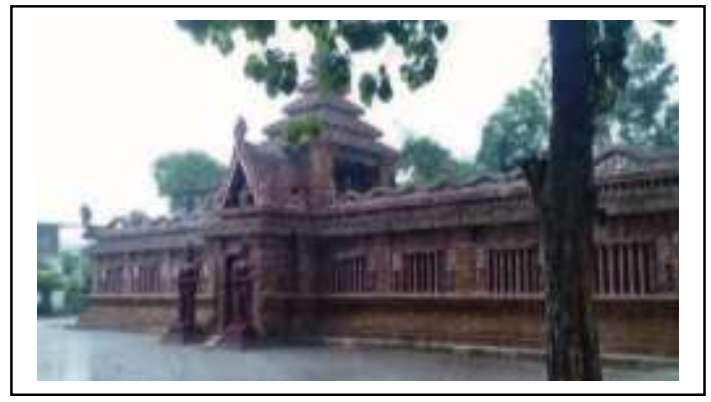

(b)

Fig. 2. (a) Detudom Provincial Court, Ubon Ratchathani ; (b) Wat Ban Pluai Yai, Roi Et. (Source: $h$ ttps://dudc.coj.go.th/th/page/item/index/id/1; https://www.facebook.com/swp.pr/)

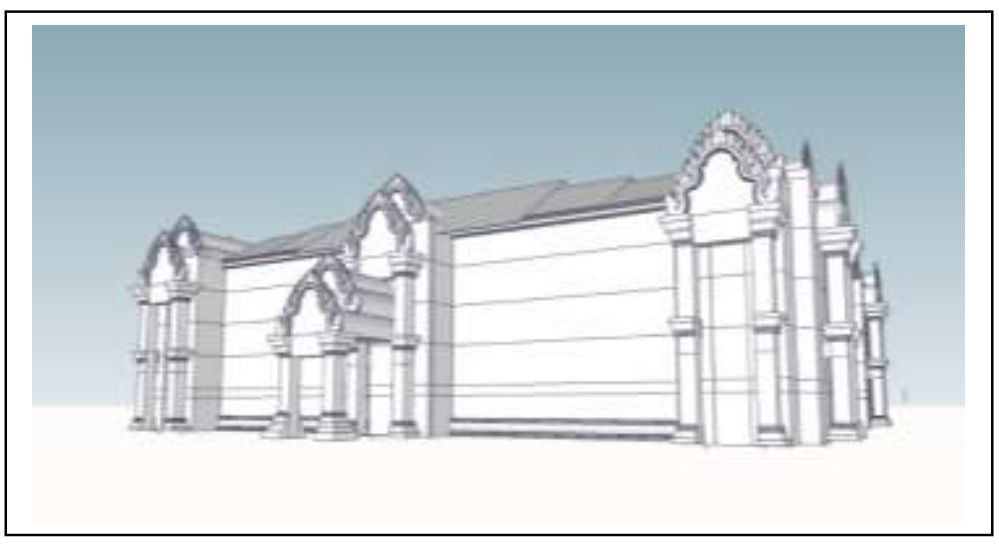

Fig. 3: The sample in the questionnaire

The testing with the perception process is reliable (Lynch, 1960; Prak, 1977; Stamps \& Nasar, 1997; Gifford, 1999; Zanordin, Abdullah \& Baharum, 2012; Kiruthiga \& Thirumaran, 2016; Hegzi \& Abdel-Fatah, 2017). The exercises of local identity design were practiced to architectural studio design. Come up with some critiques; the designate approached the contemporary style. This research used the perspective image from SketchUp to be a sample in the questionnaire.

\subsection{Questionnaire design.}
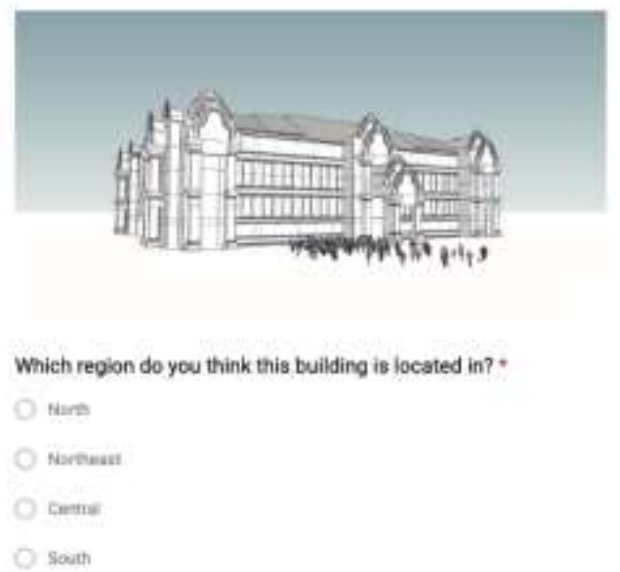

Fig. 4 The questionnaire 
Data collection was planned for simple sampling and distributing online. The media used in the questionnaire were electronic media. It gave results not different from the paper questionnaire, but it was able to separate information and answer queries more quickly (Yun \& Trumbo, 2000; Swoboda et al., 1997 in Andrews et al., 2003). The use of electronic questionnaires reduces the color discrepancy and the resolution of images from the publication in the paper. Some of the inexpensive printing process, the quality of the picture is less and not enough quality to fit in the questionnaires.

The questionnaire divided into two parts,

1. First part is the personal data to test some critical backgrounds of knowledge, for example.

2. The Perception test showed the city hall building redesign with the choices four regions of Thailand: North, Northeast, Central, and South (Fig.4).

The analysis used descriptive statistics to show the frequency of the data collected from the questionnaire, expressed in numbers and percentage.

\subsection{Result}

The result shows that Northeast region (Isan) has the highest number, 71.43 percent, followed by the central area, 22.45 percent, the northern part is 4.08 percent, and the southern region is 2.04 percent, respectively.

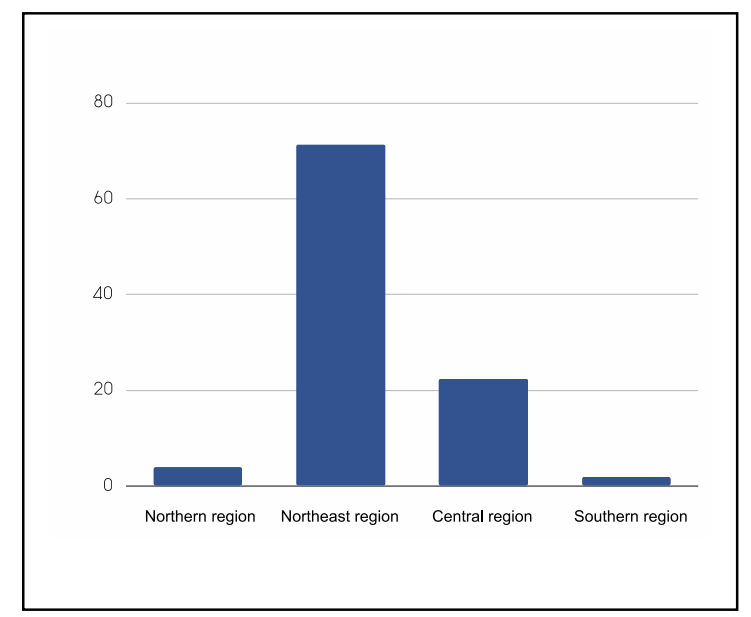

Fig. 5 Result chart

\subsection{Discussion and Summary}

There is information both support and not support the model. This information needed to be considered to further analysis. The topic divided as followings,

1. Too large building

There is no need to build a large-scale structure as the Western model, strange roof scale, or the building scale is oppressed people. The Roi Et city hall was built under the city hall construction standard with five stories high. This standard adopts the model creates the inappropriateness. The scale may need to be reduced and add more human dimension elements of the five stories building. This dimension makes the large-scale construction become more Human-related and be less oppressed.

\section{Building Shape}

The building should represent humbleness instead of oppression. In this topic, the consideration of the original shape under the city hall model standard may depend on other factors as well, whether it is management, convenience, or budget. Also, the dimension of space should be adjusted by managing the interior space. It requires further research to investigate the users' habit in the present. These behaviors may relate to the building image form other perspectives.

3. Elements management

Such as how to put elements of the façade, to justify the identity expression, the only façade cannot access the internal space that expresses the South Isan local identity. The use of elements in the design of this city hall that has changed from Thai style to the Kopura façade, which is a popular architectural style in South Isan.

4. Chosen elements

The chosen elements may not follow the original Kopura pattern. The design adjusts the appearance of the exterior to be contemporary and be interpreted, adapted, reduced, to be used in nowadays. By studying the identity recognition in the South Isan, the perception of the building image, that is the most apparent visual perception, has the characteristics which represent the Southern Isan identity.

By considering architectural elements of the former Roi Et city hall building, the language to represent the local identity in the city hall needs to be more complex because it has to communicate with two levels (Suwatcharapinan et al., 2012). At the first level, the 
architecture must link to the culture inspired. And the second level, architecture is needed to communicate to the building users inevitably. This communication means the conditions for choosing the language in architectural design to represent local identity depends on the level of recipients that we want to communicate. The city hall design added the local character so that the recognition level should be understandable, visible, and recognizable. The chosen language about the architecture with local identities such as shape, roof, or other elements must combine with the current design method to interact with the usage of the area. This view is one of a new issue that should be studied further. The questions such as what describes the pattern of local identity in the government buildings, what the specific implications of a government building are, are some of the items to the further study.

By the conclusions, the results can reveal a local identity of the South Isan in the Roi Et city hall building perception at 71.43 percent of the survey answer. Along with the explanation of the appropriateness of the façade of the city hall building which is supporting contents. This obtained reflection from the visual perception still depends on many other factors such as the proportion according to the standard, elements management of the city hall building, communication level of the local identity which can all adapt to the future city hall design.

\section{Acknowledgments}

We want to express our special thanks to the Office of Natural Resources and Environmental Policy and Planning, who supported us to do this project.

\section{References}

Andrews, D., Nonnecke, B., \& Preece, J. (2003). Conducting Research on the Internet: Online Survey Design, Development and Implementation Guidelines International Journal of Human Computer Interaction, 2(16), 185-210. Retrieved 2019, from http://citeseerx.ist.psu.edu/viewdoc/download?doi=10.1.1.91.4972\&rep=rep1\&type=pdf

Churstarponsiri, N. (2001). Political meaning of the architecture of Thai government house. Unpublished Master's thesis. Chulalongkorn University, Faculty of Political Science.

Gifford, R. (1999). Environmental Perception and Cognition, Translated by Nasrin Dehbashi, Journal of Architecture and Culture.

Hegzi, Y.S. \& Abdel-Fatah, N.A. (2017). Quantifying students' perception for deconstruction architecture. Ain Shams Engineering Journal, 9, $2745-2754$.

Kiruthiga, K., \& Thirumaran K. (2016). Visual perception on the architectural elements of the built heritage of a historic temple town: A case study of Kumbakonam, India. Frontier of Architectural Research (2017), 6, 96-107.

Li, T.L. (2007). A study of Ethic Influence on the Façade of Colonial shophouse in Singapore: A case study of Telok Ayer in Chinatown. Ph.D. University of Tokyo.

Lorchai, L., Panin, O., \& Kerdsiri, K. (2015). Spatial Characteristics in Vernacular Architecture: Approaches to the design of contemporary architecture. Journal of environment design, 2(2).

Lynch, K. (1960). The Image of the City. Cambridge: MIT Press.

Phetsuriya, N. (2013). The Preferences of Lampang shophouses' facades. Unpublished Master's thesis. Chiangmai University, Faculty of Architecture.

Prak, N.L. (1977). The visual perception of the built environment. Delft: Delft University Press.

Saiseng, N. (2017). Human Nature and Spatial Perspective. Veridian E-Journal, Silpakorn University, 1(10), 635-646.

Sanboon, T. (2014). "Khmer style" in the form of Isan technicians in Thai contemporary. Art and Cultural magazine. Retrieved February 27, 2019, form website: https://www.silpa-mag.com/history/article_8380

Stamps, A.E., \& Nasar, J.L. (1997). Design Review and Public Preferences: Effects of Geographical location, Public consensus, Sensation seeking, and Architecture styles. Journal of Environmental Psychology (1997), 17, 11-32.

Sutthitham, T. (2001). Settlement plants in Thailand: the land use and change in Khmer settlements in the Northeast. Khonkaen: Khonkaen Pim Phattana Publishing

Suwatcharapinan, S., Kaittiweerasak, T., and Littisorn, R. (2012). Semiology: Decoding and Applying Thai identities for Design Guidelines. Built Environment Research Associates Conference, May 25, 2012 at Thammasat University.

The Secretariat of the Cabinet. (2010). Committee of Government System Management Meeting 2/2010. Retrieved February 27, 2019, form website: http://www.cabinet.soc.go.th/soc/Program2-3.jsp?top_serl=224305

Tok, Y.S., Kaplan, I., \& Taneli, Y. (2010). Photography in architectural education: A tool for assessing social aspects of the built environment. ScienceDirect Procedia Social and Behavioral Sciences, 2, 2583-2588

Wongthes, S. (2012). Where did Roi Et come from. Bangkok: Chonniyom Publishing.

Zainordin, N., Abdullah, S.M., \& Baharum, Z.A. (2012). Light and space: Users perception towards energy efficient buildings. Procedia-Social and Behavioral Sciences $36,51-60$. 